\title{
LETTER
}

\section{A lung point that is not a lung point}

Giovanni Volpicelli* ${ }^{*}$

(c) 2019 Springer-Verlag GmbH Germany, part of Springer Nature

Dear Editor,

I read with interest the case reported by Steenvoorden et al. [1]. The title of the paper is very appealing, claiming that they report a rare case where lung point was present in the absence of pneumothorax. However, the video included as supplementary material to the article clearly does not show any lung point. For this reason, the title of the case should be changed. In video B, I see an area with regular sliding and an area without sliding, but there is no interposition between the two. In other words, the sliding zone does not "slide", alternating during respiration and replacing the non-sliding zone. This definition of the lung point is clearly written in the 1st International Consensus Conference on lung ultrasound and should always represent a guide for non-experts and experts [2]. The correct definition of lung point is "a point on the chest wall where a respiratory pattern... is visualized again and intermittently replaces the motionless pleura" [3]. In the aforementioned video, it is easy to appreciate in real time that the pattern is not due to a lung point, but to the coexistence in the same image of two areas, one regularly ventilating and the other that is not. This is not rare but a common finding in complex situations, like in adherences, previous thoracic surgeries, thoracic blunt trauma, and so on. Moreover, very often the non-ventilating areas show B-lines or other ultrasound signs of parenchymal conditions, which are of great help to rule out pneumothorax, as is clearly noted by Steenvoorden et al. in their case (B-line).

Compliance with ethical standards

Conflicts of interest

The author declares no conflict of interest in the subject matter.

\section{Publisher's Note}

Springer Nature remains neutral with regard to jurisdictional claims in published maps and institutional affiliations.

Accepted: 28 March 2019

Published online: 17 April 2019

\section{References}

1. Steenvoorden TS, Hilderink B, Elbers PWG et al (2018) Lung point in the absence of pneumothorax. Intensive Care Med 44:1329

2. Volpicelli $\mathrm{G}$ et al (2012) International evidence-based recommendations for point-of-care lung ultrasound. Intensive Care Med 38:577-591

3. Volpicelli G (2011) Sonographic diagnosis of pneumothorax. Intensive Care Med 37:224-232

\section{Springer}

